\title{
The molecular phenotype of human cardiac myosin associated with hypertrophic obstructive cardiomyopathy
}

\author{
Adam M. Jacques ${ }^{1}$, Natalia Briceno ${ }^{1}$, Andrew E. Messer ${ }^{1}$, Clare E. Gallon ${ }^{1}$, Shapour Jalilzadeh ${ }^{2}$, \\ Edwin Garcia1, Gaelle Kikonda-Kanda1, Jennifer Goddard², Sian E. Harding ${ }^{1}$, Hugh Watkins ${ }^{2}$, \\ M. Tomé Esteban ${ }^{3}$, Victor T. Tsang ${ }^{3}$, William J. McKenna ${ }^{3}$, and Steven B. Marston ${ }^{1 *}$ \\ ${ }^{1}$ Cardiac Medicine, National Heart and Lung Institute, Imperial College London, Guy Scadding Building, Dovehouse Street, \\ London, UK; ${ }^{2}$ Department of Cardiovascular Medicine, John Radcliffe Hospital, Oxford, UK; and ${ }^{3}$ Institute of Cardiovascular \\ Science, University College London, London, UK
}

Received 20 August 2007; revised 3 March 2008; accepted 31 March 2008; online publish-ahead-of-print 14 April 2008

Time for primary review: 37 days

\section{KEYWORDS}

Contractile apparatus;

Contractile function;

Hypertrophy;

Protein phosphorylation;

Myosin;

Myectomy;

Hypertrophic cardiomyopathy

\begin{abstract}
Aim The aim of the study was to compare the functional and structural properties of the motor protein, myosin, and isolated myocyte contractility in heart muscle excised from hypertrophic cardiomyopathy patients by surgical myectomy with explanted failing heart and non-failing donor heart muscle. Methods Myosin was isolated and studied using an in vitro motility assay. The distribution of myosin light chain-1 isoforms was measured by two-dimensional electrophoresis. Myosin light chain-2 phosphorylation was measured by sodium dodecyl sulphate-polyacrylamide gel electrophoresis using Pro-Q Diamond phosphoprotein stain.

Results The fraction of actin filaments moving when powered by myectomy myosin was $21 \%$ less than with donor myosin $(P=0.006)$, whereas the sliding speed was not different $(0.310 \pm 0.034$ for myectomy myosin vs. $0.305 \pm 0.019 \mu \mathrm{m} / \mathrm{s}$ for donor myosin in six paired experiments). Failing heart myosin showed $18 \%$ reduced motility. One myectomy myosin sample produced a consistently higher sliding speed than donor heart myosin and was identified with a disease-causing heavy chain mutation (V606M). In myectomy myosin, the level of atrial light chain-1 relative to ventricular light chain-1 was $20 \pm 5 \%$ compared with $11 \pm 5 \%$ in donor heart myosin and the level of myosin light chain-2 phosphorylation was decreased by $30-45 \%$. Isolated cardiomyocytes showed reduced contraction amplitude $(1.61 \pm 0.25$ vs. $3.58 \pm 0.40 \%)$ and reduced relaxation rates compared with donor myocytes $\left(\mathrm{TT}_{50 \%}=\right.$ $0.32 \pm 0.09$ vs. $0.17 \pm 0.02 \mathrm{~s}$ ).

Conclusion Contractility in myectomy samples resembles the hypocontractile phenotype found in endstage failing heart muscle irrespective of the primary stimulus, and this phenotype is not a direct effect of the hypertrophy-inducing mutation. The presence of a myosin heavy chain mutation causing hypertrophic cardiomyopathy can be predicted from a simple functional assay.
\end{abstract}

\section{Introduction}

Hypertrophic cardiomyopathy is a primary disease of cardiac muscle and is clinically defined as a hypertrophied, nondilated left ventricle in the absence of any other aetiology. It is a common cardiac disorder affecting one in 500 of the population and is the leading cause of sudden death in the

*Corresponding author. Tel: +44 207351 8147; fax: +44 2078233392.

E-mail address: s.marston@imperial.ac.uk young. It has been known for some time that hypertrophic cardiomyopathy is usually familial and has been linked to mutations in the contractile apparatus of cardiac muscle. Although mutations have been identified in every component of the muscle sarcomere, the most common contractile protein mutations that cause hypertrophic cardiomyopathy are in $\beta$ myosin heavy chain (MYH7 gene) and myosin-binding protein-C (MYBPC3 gene) which make up 25 and $26 \%$ of all hypertrophic cardiomyopathy cases, respectively. ${ }^{1-4}$

Published on behalf of the European Society of Cardiology. All rights reserved. (C) The Author 2008

For permissions please email: journals.permissions@oxfordjournals.org

The online version of this article has been published under an open access model. Users are entitled to use, reproduce, disseminate, or display the open access version of this article for non-commercial purposes provided that the original authorship is properly and fully attributed; the Journal, Learned Society and Oxford University Press are attributed as the original place of publication with correct citation details given; if an article is subsequently reproduced or disseminated not in its entirety but only in part or as a derivative work this must be clearly indicated. For commercial re-use, please contact journals.permissions@oxfordjournals.org 
Many mutations identified as causing hypertrophic cardiomyopathy have been investigated with recombinant proteins incorporating the mutation or in transgenic mouse models. In vitro the mutations usually cause a gain in function, with increased rate of crossbridge turnover and increased $\mathrm{Ca}^{2+}$ sensitivity ${ }^{1,5-8}$ but this does not necessarily translate into enhanced contractility in animal models. ${ }^{9,10}$ The mechanism relating the initial mutation to the development of pathological hypertrophy is still not understood, ${ }^{11}$ nor do we know whether transgenic models of hypertrophic cardiomyopathy are directly relevant to hypertrophic cardiomyopathy as observed in human hearts.

Very few investigations have been made with heart muscle from patients with hypertrophic cardiomyopathy. $8,12,13$ The main reason for this has been the unavailability of suitable material. Heart punch biopsies are rarely justified and yield insufficient material for extensive functional analysis. However, a subset of hypertrophic cardiomyopathy patients (about 25\%) have left ventricular outflow tract obstruction (LVOTO) caused by the contact between the mitral valve leaflet and the hypertrophied interventricular septum in systole. LVOTO is associated with an increased risk of sudden death and therefore justifies intervention. ${ }^{14}$ The surgical septal myectomy operation removes 3-7 g of myocardium from the interventricular septum in the region of the obstruction ${ }^{15,16}$ and the excised muscle is a unique source of human heart muscle with hypertrophic cardiomyopathy.

We have compared the functional and structural properties of myectomy muscle with end-stage failing and non-failing donor heart muscle to determine the molecular phenotype of hypertrophic cardiomyopathy muscle and ultimately to link this to the disease-causing mutation. Our initial studies, reported here, investigated the functional properties of isolated myocytes and of the motor protein, myosin, extracted from myectomy, failing and donor heart muscle measured by in vitro motility assay. We have found that myocytes are hypocontractile, and the fraction of actin filaments moving when powered by myectomy myosin is significantly lower than the control myosin, indicating dysfunction at the molecular level. In addition, the expression of atrial light chain-1 (ALC-1) relative to ventricular light chain-1 (VLC-1) in myectomy myosin is higher and the level of myosin light chain-2 (MLC-2) phosphorylation is lower. This pattern of results was found in every myectomy sample independent of the mutation that is presumed to initiate hypertrophy. One myosin sample showed a higher sliding speed than donor myosin which we predicted was due to a disease-causing mutation in myosin heavy chain (MHC) and this was confirmed by genotyping the tissue.

\section{Methods}

\subsection{Collection and storage of human myocardium}

\subsubsection{Hypertrophic cardiomyopathy}

Human myocardial samples were obtained from patients with hypertrophic cardiomyopathy undergoing surgical septal myectomy for relief of LVOTO. For in vitro motility assay, the samples were snap-frozen in liquid nitrogen and stored for later use. Local ethical approval was obtained from University College London Hospitals and the Brompton, Harefield and NHLI ethics committees for collection and use of tissue samples. All patients had cardiac investigations, including 12-lead ECG, chest X-ray, Holter monitor, cardiopulmonary exercise test, two-dimensional transthoracic echocardiography, transoesophageal echocardiography, cardiac catheterization, and coronary angiography (Table 1).

\subsubsection{Non-failing and failing heart muscle}

Tissue samples were supplied by Prof. C. Dos Remedios, University of Sydney, Australia. Ethical approval was obtained from the Brompton, Harefield and NHLI Research Ethics Committee, London, and St Vincent's Hospital, Sydney. The investigation conformed with the principles outlined in the Declaration of Helsinki. We studied tissue from nine explanted hearts with end-stage heart failure (ejection fraction $<20 \%$ ) and eight non-failing donor hearts. The donor heart tissue was obtained from hearts where no suitable transplant recipient was found. The patients had no history of cardiac disease, a normal cardiac examination, normal ECG, and normal ventricular function on echocardiography within $24 \mathrm{~h}$ of heart explantation. Myocardium was immediately frozen in liquid nitrogen and stored for later analysis or stored in cardioplegic solution for cell isolation. Clinical and functional characteristics of these donor and failing heart samples have been previously reported. ${ }^{17}$

\subsection{Myosin extraction from human heart muscle}

Fifty milligrams of human cardiac tissue were crushed using a liquid-nitrogen-cooled percussion mortar and homogenized in $0.25 \mathrm{~mL}$ ice-cold high salt extraction buffer $\left(0.3 \mathrm{~mol} / \mathrm{L} \mathrm{KCl}, 0.15 \mathrm{~mol} / \mathrm{L} \mathrm{K}_{2} \mathrm{HPO}_{4}, 10 \mathrm{mmol} / \mathrm{L} \mathrm{Na} \mathrm{P}_{2} \mathrm{O}_{7}\right.$, $1 \mathrm{mmol} / \mathrm{L} \mathrm{MgCl}_{2}, 1 \mathrm{mmol} / \mathrm{L} \mathrm{MgATP}, 10 \mathrm{mmol} / \mathrm{L}$ DTT, $3 \mu \mathrm{g} /$ $\mathrm{mL}$ each of protease inhibitors, chymostatin, pepstatin $A$, leupeptin, and E64, pH 6.8). The homogenate was extracted at $4{ }^{\circ} \mathrm{C}$ for $1 \mathrm{~h}$ on a rotating mixer and then centrifuged for $20 \mathrm{~min}$ at $337000 \mathrm{~g}$. The supernatant was collected and diluted $\times 20$ with ice-cold $5 \mathrm{mmol} / \mathrm{L}$ DTT and allowed to precipitate on ice for $1 \mathrm{~h}$. It was then spun for $20 \mathrm{~min}$ at 26000 $g$ at $4{ }^{\circ} \mathrm{C}$ to collect the precipitated myosin. ${ }^{8}$ The pellet obtained was dissolved in $250 \mu \mathrm{L}$ of resuspension buffer $(0.3 \mathrm{~mol} / \mathrm{L} \mathrm{KCl}, 25 \mathrm{mmol} / \mathrm{L}$ imidazole, $\mathrm{pH} 7.4,1 \mathrm{mmol} / \mathrm{L}$ EGTA, $4 \mathrm{mmol} / \mathrm{L} \mathrm{MgCl}_{2}, 10 \mathrm{mmol} / \mathrm{L}$ DTT, $1.4 \mu \mathrm{L}$ each of $2.5 \mathrm{mg} / \mathrm{mL}$ chymostatin, pepstatin, leupeptin, and E64). The concentration of myosin was determined using the Bradford assay and the purity was assessed using sodium dodecyl sulphate-polyacrylamide gel electrophoresis (SDS-PAGE; Figure 2). Using this method, $1 \mathrm{mg}$ of myosin can be obtained from $50 \mathrm{mg}$ of tissue. Skeletal muscle actin and human cardiac muscle tropomyosin and troponin were prepared as previously described. ${ }^{17}$ The preparation of myofibrils from human heart samples is described in the Supplementary material.

\subsection{In vitro motility assay}

The in vitro motility assay technique was used to study TRITC-phalloidin-labelled actin filaments moving over immobilized myosin. ${ }^{18}$ Detailed protocols are provided in Supplementary material.

\subsection{Assay of myosin light chains}

Light chain isoforms were analysed by two-dimensional electrophoresis. Thirty micrograms of muscle homogenate were separated by isoelectric focussing on 18-cm long, pl 4.5-5.5, 


\begin{tabular}{|c|c|c|c|c|c|c|}
\hline Biopsy sample & M1 & M3 & M4 & M5 & M7 & M8 \\
\hline Diagnosis & $\mathrm{HCM}$ & $\mathrm{HCM}$ & $\mathrm{HCM}$ & $\mathrm{HCM}$ & $\mathrm{HCM}$ & $\mathrm{HCM}$ \\
\hline Age & 24 & 42 & 49 & 31 & 54 & 42 \\
\hline Myectomy date & $23 / 06 / 04$ & 04/08/04 & $04 / 08 / 04$ & $11 / 08 / 04$ & $22 / 09 / 04$ & $17 / 11 / 04$ \\
\hline Gender & $\mathrm{F}$ & M & M & M & $\mathrm{F}$ & M \\
\hline Diagnosed & 2001 & 2002 & 1994 & 1996 & 1992 & 1999 \\
\hline Family history & No HCM; no SCD & No HCM; no SCD & Father died 58 years & $\begin{array}{l}\text { No HCM; no SCD; nine } \\
\text { siblings; negative } \\
\text { screen }\end{array}$ & $\begin{array}{l}\text { No SCD; one sister w/ } \\
\text { possible HCM }\end{array}$ & $\begin{array}{l}\text { Mother SCD; } 47 \text { years } \mathrm{HCM} \\
\text { at post-mortem }\end{array}$ \\
\hline Current treatment & Verapamil, amiodarone & Atenolol, disopyramide & $\begin{array}{l}\text { Atenolol, aspirin, } \\
\text { disopyramide, clopidogrel, } \\
\text { quinine }\end{array}$ & Propanolol & $\begin{array}{l}\text { Atenolol, aminodarone, } \\
\text { frumil }\end{array}$ & Disopyramide, timolol \\
\hline ECHO appearance & ASH & ASH & Concentric LVH & Mild ASH & ASH & ASH \\
\hline MaxLVWT (mm) & 27.5 & 23 & 16 & 20 & 22 & 23 \\
\hline Max. ST (mm) & 27.5 & 23 & 16 & 20 & 22 & 23 \\
\hline LVEDD (mm) & & 43.6 & 42.0 & 39.0 & 44.0 & 34.0 \\
\hline LVESD (mm) & & 23.9 & 28.0 & 21.0 & 23.0 & 12.0 \\
\hline LA $(\mathrm{mm})$ & 45 & 41 & 48 & 41 & 43 & 44 \\
\hline FS (\%) & & 45 & 33 & 48 & 46 & 64 \\
\hline SAM & Complete & Incomplete & Complete & Complete & Incomplete & Complete \\
\hline MR & Mild & Mild & Mild to moderate & Trivial & Mild & Trivial \\
\hline $\begin{array}{l}\text { Resting LVOT } \\
\text { gradient } \\
\text { (mmHg) }\end{array}$ & 86 & 22 (133 mmHg with GTN) & 104 & 110 & 20 (stress, 190 mmHg) & 93 \\
\hline $\begin{array}{l}\text { VT on holter } \\
\text { monitor }\end{array}$ & VT (non- sustained) & No & Isolated VEs only & No & VT (non-sustained) & No \\
\hline $\begin{array}{l}\text { ETT MVO2 (ml/ } \\
\mathrm{min} / \mathrm{kg})\end{array}$ & $\begin{array}{l}\text { 58\% predicted; no } \\
\text { arrhythmias; flat BP }\end{array}$ & $\begin{array}{l}20.3 ; 68 \% \text { predicted; no } \\
\text { arrhythmias BP rise }\end{array}$ & $\begin{array}{c}11.7 ; 35 \% \text { predicted; no } \\
\text { arrhythmias; flat BP }\end{array}$ & $\begin{array}{l}62 \% \text { predicted; no } \\
\text { arrhythmia; flat BP }\end{array}$ & $\begin{array}{l}\text { 15.8; } 77 \% \text { predicted; no } \\
\text { arrhythmia; BP rise }\end{array}$ & $\begin{array}{c}\text { 15.0; } 42 \% \text { predicted; no } \\
\text { arrhythmias; BP rise }\end{array}$ \\
\hline ECG & SR, LVH, RA & SR, LVH, RA & SR, LVH & SR, LVH & SR, LVH, RA & SR, LVH, RA \\
\hline NYHA class & II & II-III & II & III & III & III \\
\hline
\end{tabular}


Immobiline strips (GE Biosciences), and by SDS-PAGE in the second dimension. ${ }^{19}$ The gels were stained with SYPRO Ruby (Invitrogen).

One-dimensional SDS-PAGE gels were used to analyse the levels of phosphorylation using the Pro-Q Diamond stain developed by Molecular Probes (Invitrogen). ${ }^{20}$ Myofibrils or myosin $(10-20 \mu \mathrm{g})$ was separated on $10 \times 12 \mathrm{~cm}$ gels (8-18\% Polyacrylamide gradient, 1\% SDS: Exelgel, GE Biosciences). The gel was stained with Pro-Q Diamond according to the manufacturer's instructions and the phosphoprotein bands were visualized by UV transillumination and recorded with a digital camera (Gene Genius/ CHEMI-HR16 system, Synoptics). The gel was then re-stained with SYPRO Ruby or Coomassie Blue total protein stains. The Pro-Q Diamond band volume from densitometric analysis was normalized to the corresponding total protein band volume.

\subsection{Isolation and characterization of cardiomyocytes}

Myocytes were isolated from fresh myectomy or transplant tissue and analysed as described previously. ${ }^{21}$ Detailed protocols are provided in the Supplementary material.

\subsection{Genotyping}

Screening for mutations was performed by high-resolution melting curve analysis on a Lightscanner (Idaho Technology, Inc.) with LCGreen Plus dye. Genomic DNA samples were quantitated with Nanodrop, quality-checked by gel electrophoresis, and each exon was then PCR-amplified. To promote heteroduplex formation, samples were subsequently denatured by heating to $95^{\circ} \mathrm{C}$ for $30 \mathrm{~s}$ and cooled to $20^{\circ} \mathrm{C}$. Plates were centrifuged and immediately run on the Lightscanner instrument according to the manufacturer's recommendations. Amplimers with aberrant melting curves were then investigated by bidirectional sequencing.

\section{Results}

\subsection{Properties of myocytes extracted from myectomy muscle}

Ventricular myocytes from myectomy samples had a varied morphology, with some cells showing a clear rod-shaped morphology, such as those in samples from non-failing or failing ventricles, but others with a highly branched appearance (Figure 1A). Surprisingly, contraction amplitudes in myocytes from myectomy samples were low, or lower than in those from failing hearts studied during the same period, and relaxation was more impaired. Figure $1 B \mathrm{com}$ pares myocytes at $2 \mathrm{mmol} / \mathrm{L} \mathrm{Ca}^{2+}$, where amplitude was significantly lower in myectomy samples than in failing. Relaxation had a strong tendency to be slower (Figure 1) and was certainly more variable (comparison of variances $P<0.001$, comparison of means with Welch's correction for unequal variances, $P=0.058$ ). Relaxation times for myocytes from failing heart shown here were similar to those previously described from this laboratory, where relaxation times were significantly longer than those for non-failing hearts. ${ }^{24}$ At $4 \mathrm{mmol} / \mathrm{L} \mathrm{Ca}^{2+}$, the amplitude difference between myectomy and failing myocytes was reduced (\% shortening: myectomy $2.83 \pm 0.41 \%, 34$ cells $/ 17$ patients, failing $3.28 \pm 0.21 \% 110$ cells $/ 40$ patients), but the relaxation deficit and high variability was maintained $\left(\mathrm{R}_{90}\right.$ : myectomy, $0.76 \pm 0.11 \mathrm{~s}$, failing, $0.51 \pm 0.02 \mathrm{~s}$, comparison of variances $P<0.001$, comparison of means with Welch's correction for unequal variances, $P<0.05)$.

\subsection{Altered motility function of myectomy myosin}

We studied myosin in six heart muscle samples from patients with hypertrophic obstructive cardiomyopathy (HOCM) undergoing septal myectomy $(M)$ and compared these with myosin from donor heart left ventricle muscle $(\mathrm{N})$. Table 1 shows the clinical details of the HOCM patients. For functional studies, myosin was extracted from $50 \mathrm{mg}$ samples of frozen heart muscle by a method based on Palmiter et al. ${ }^{8}$ (Figure 2). In vitro motility assay using freshly prepared myectomy myosin showed that TRITC-phalloidinlabelled actin filaments moved at a mean speed of $0.310 \pm$ $0.034 \mu \mathrm{m} / \mathrm{s}$ at $30^{\circ} \mathrm{C}$. Myectomy muscle sliding speed was not significantly different from the donor heart controls $(0.305 \pm 0.019 \mu \mathrm{m} / \mathrm{s})$. Comparison of the fraction of actin filaments that were motile showed that all of the myectomy myosin muscle samples produced a $21 \%$ lower fraction motile than the donor control heart myosin $[0.54 \pm 0.03$ for myectomy myosin compared with $0.69 \pm 0.4$ for control, $P<0.001, n=20$ (four measurements each from five paired myosin preparations); see Figure $3 \mathrm{~A}$ and $\mathrm{B}]$.

We also compared the donor myosin $(\mathrm{N})$ with myosin from end-stage failing heart muscle $(F)$ using the same preparation method. The fraction of filaments moving was $15 \%$ lower in the failing heart muscle (donor, $0.73 \pm 0.02$; failing, $0.63 \pm$ $0.03, P=0.0002$ ) and the sliding speed was $11 \%$ lower and this difference was also significant (Figure $3 \mathrm{C}$ and D).

The addition of $50 \mathrm{mmol} / \mathrm{L}$ human cardiac tropomyosin had very little effect on the fraction of filaments motile or filament sliding speed. In the presence of $40 \mathrm{nmol} / \mathrm{L}$ human cardiac troponin, the motility of thin filaments reconstituted with $10 \mathrm{nmol} / \mathrm{L}$ TRITC-F-actin and $50 \mathrm{nmol} / \mathrm{L}$ tropomyosin was regulated by $\mathrm{Ca}^{2+}$ (Figure 4). At activating $\mathrm{Ca}^{2+}$ concentrations, the fraction of filaments motile was slightly higher for pure actin, $0.76 \pm 0.04$ for donor control myosin, and $0.61 \pm 0.09$ for myectomy myosin. The lower fraction motile of myectomy myosin is thus still observed in fully reconstituted thin filaments. As previously observed, ${ }^{22,23}$ the sliding speed of $\mathrm{Ca}^{2+}$-activated thin filaments was greater than that of pure actin filaments, by $10 \%$ for donor myosin and by $36 \%$ for myectomy myosin. In relaxing conditions ( $\mathrm{pCa} 9)$, thin filament motility was switched off with both myectomy and donor heart myosin. An exception to this pattern was myosin from myectomy sample M5 which showed no relaxation in this experiment: in fact, the fraction of thin filaments motile was greater at pCa9 than pCa5. The myosin preparations were too unstable to permit determination of $\mathrm{Ca}^{2+}$ dose-response curves.

As impaired relaxation in in vitro motility assays is a feature of many mutations that are associated with hypertrophic cardiomyopathy, we examined M5 myosin further to determine whether it exhibited other characteristics in common with hypertrophic cardiomyopathy-inducing mutations (Table 2). In three series of paired comparisons with N6, M5 showed a consistently higher sliding speed ranging from 18 to $60 \%$ greater than N6 and observable with pure actin, actin-tropomyosin, and in fully reconstituted thin filaments at pCa5. Relaxation was also less 
(A)

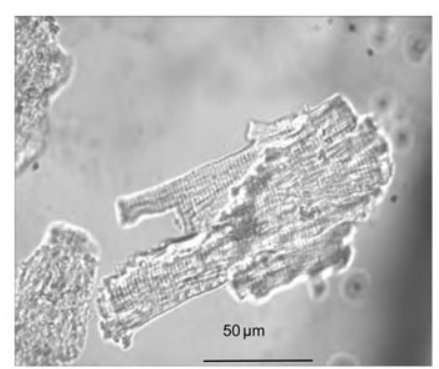

Myectomy

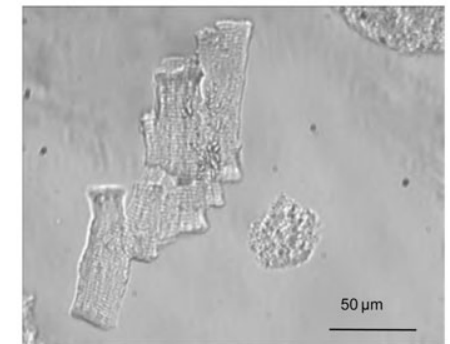

Myectomy

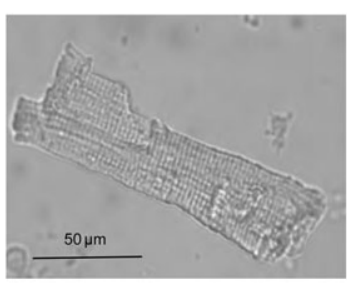

Failing

(B)

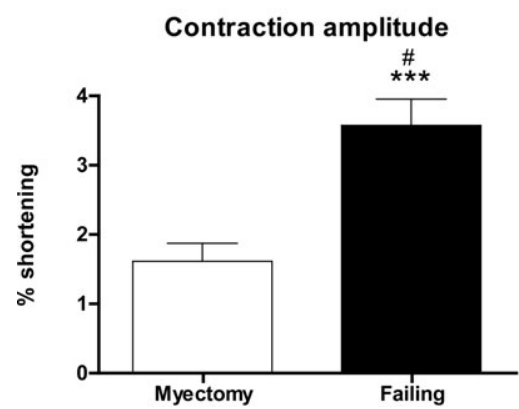

Time-to- $50 \%$ relaxation

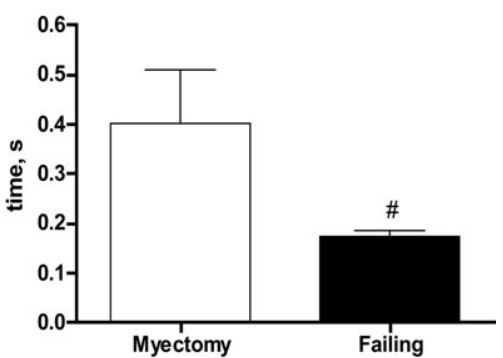

Figure 1 Contraction of isolated myocytes from myectomy muscle. (A) Two ventricular myocytes from myectomy samples, showing branched appearance, compared with the more usual rod-shaped appearance of a ventricular myocyte from failing heart. $(B)$ Contraction amplitude (\% shortening) and time-to-50\% relaxation of ventricular myocytes from myectomy ( 21 myocytes $/ 10$ hearts) and failing (41 myocytes/ 16 hearts) samples. ${ }^{\#} P<0.001$, variances significantly different; ${ }_{* * *} P<0.001$, means significantly different.

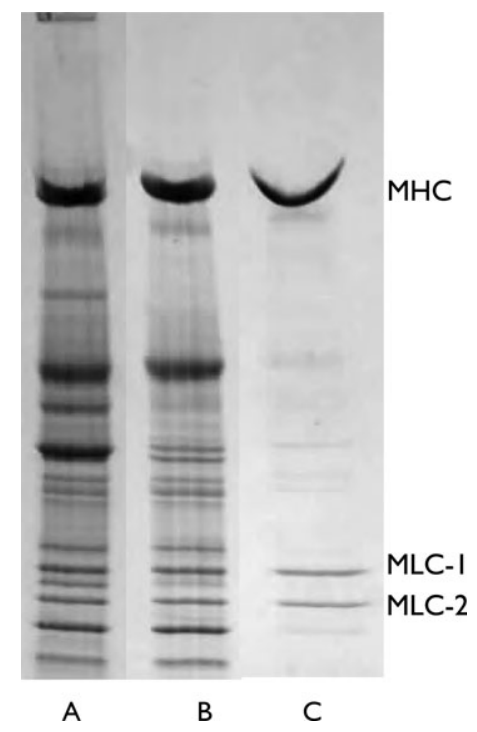

Figure 2 Isolation of myosin from human heart muscle. SDS-PAGE of $(A)$ high salt extract of muscle myofibrils, $(B)$ supernatant containing myosin and troponin-tropomyosin after ultracentrifugation, and $(C)$ pure myosin sedimented at low salt concentration. complete in $\mathrm{M} 5$ compared with N6: at pCa9 sliding speed was faster and the fraction of filaments motile was greater for $\mathrm{M5}$ myosin. All these measurements indicate a hypercontractile phenotype for M5 myosin.

\subsection{Modifications to myosin light chains}

We investigated the myosin light chains in our myectomy samples. It has been reported that ALC-1 is re-expressed in the ventricles of patients with heart failure or hypertrophy related to pressure overload. Myosin light chains were detected in muscle myofibrils by two-dimensional electrophoresis (2DE) and quantified. Compared with VLC-1, human ALC-1 has a calculated p/ 0.05 units less and a molecular weight $368 \mathrm{Da}$ more and thus should appear above and to the left of VLC-1. ALC-1 was found to be present as a small proportion of VLC-1 in all samples tested (Figure 5). On an average, the myectomy samples contained twice as much ALC-1 as the donor control group.

Multiple spots corresponding to phosphorylated and unphosphorylated MLC-2 isoforms were observed by $2 \mathrm{DE}$. However, the Pro-Q Diamond phosphoprotein stain was not sensitive enough to identify which spots were phosphorylated, therefore phosphorylation of MLC-2 was measured 
(A)

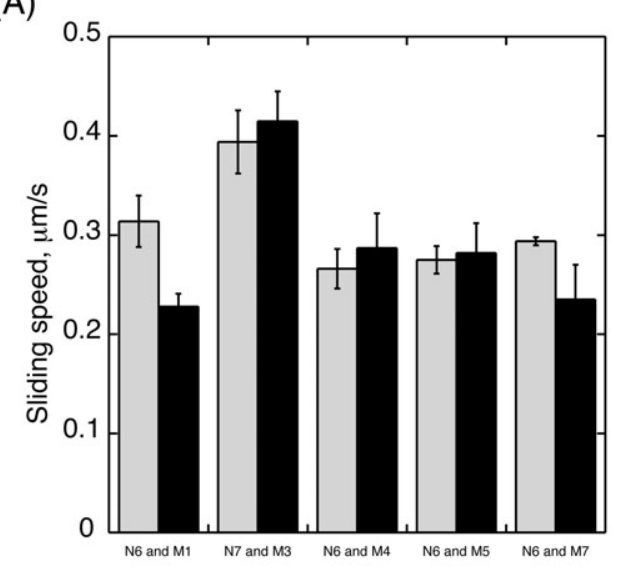

(B)

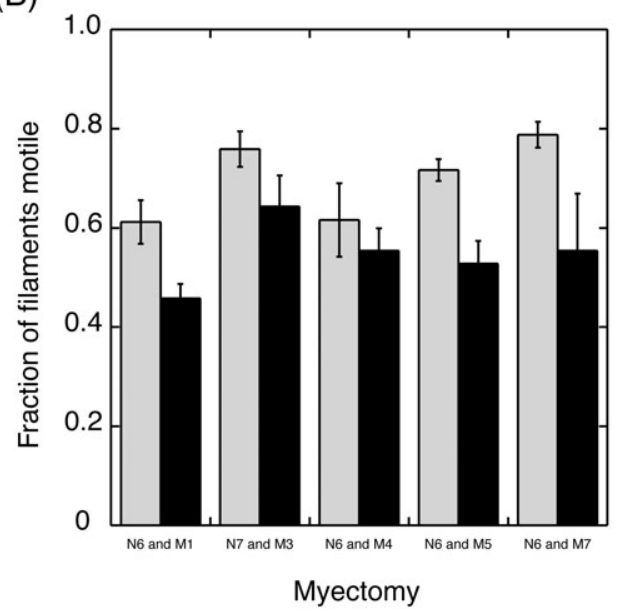

(C)

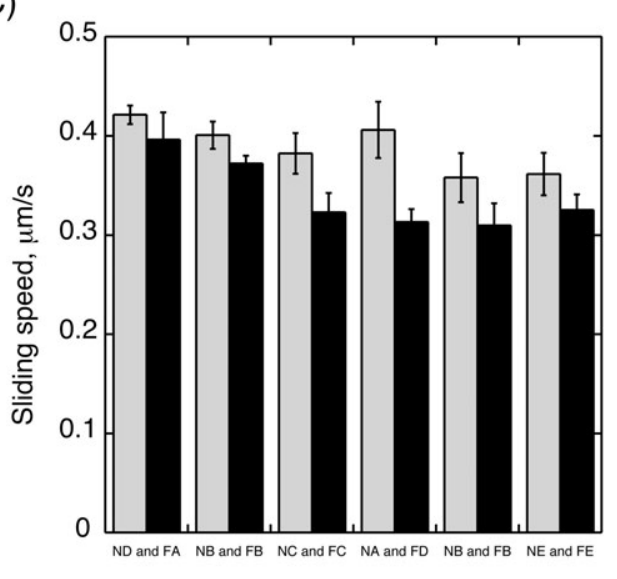

(D)

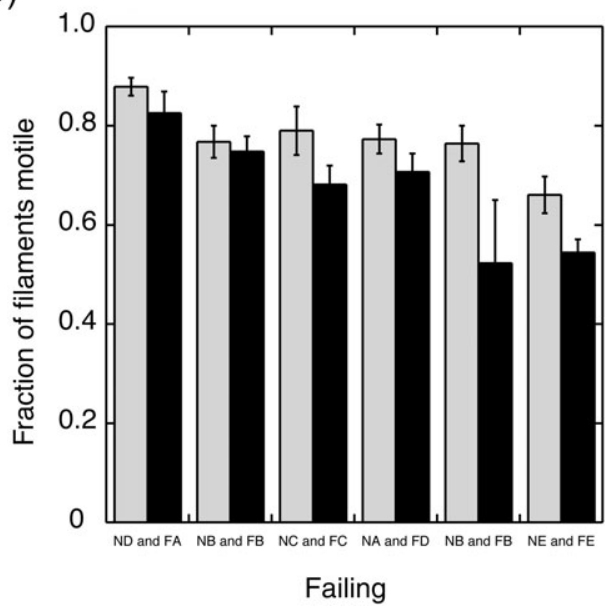

Figure 3 In vitro motility of human cardiac myosin with rabbit skeletal muscle actin. Actin filament motility was measured at $30^{\circ} \mathrm{C}$ in dual-chamber motility cells containing immobilized donor and myectomy or failing heart myosin pairs as indicated. $(A, B)$ Myosin from five myectomy samples ( $M 1$, M3, M4, M5, M7, black bars) was compared with myosin from donor muscle samples (N6 or N7, grey bars) in paired assays. Movement was analysed to yield the sliding speed $(A)$ and the fraction of filaments that were moving $(B)$. There was no systematic difference in sliding speed (mean sliding speed myectomy myosin was $94 \pm$ $0.07 \%$ of donor $P=0.44$ ), but the fraction of filaments motile was always lower with myectomy myosin (mean fraction myectomy myosin motile was $79 \pm 0.03 \%$ of donor, $P=0.004$ ). ( $C, D$ ) Myosin from failing heart muscle (FA, FB, FC, FD, FE, black bars) was compared with myosin from donor muscle (NA, NB, NC, ND, NE, grey bars) in paired assays. Movement was analysed to yield the sliding speed $(C)$ and the fraction of filaments that were moving $(D)$. Sliding speed was slightly reduced in failing heart myosin (mean sliding speed failing myosin was $89 \pm 0.03 \%$ of donor, $P=0.004$ ) and the fraction of filaments motile was also lower (mean fraction failing myosin motile was $82 \pm 0.04 \%$ of donor, $P=0.026$ ).

by one-dimensional SDS-PAGE. In muscle myofibrils, the main phosphorylated proteins were myosin-binding protein C (MyBP-C), troponin T, troponin I, and MLC-2 (Figure 6A). The level of phosphorylation, based on the Pro-Q Diamond:Coomassie blue ratio $(Q / C)$, of all these proteins was less in the myectomy samples. The average $Q / C$ of MLC-2 in myectomy samples was $56 \%$ of the level in the donor heart myofibrils (Figure 6B). We can quantify this difference on the basis of a linear relationship between phosphorylation and $Q / C$ as previously demonstrated for troponin I phosphorylation, ${ }^{17}$ taking into account the nonspecific labelling of unphosphorylated protein by Pro-Q Diamond (10\% of the non-failing signal for MLC-2). On this basis, the level of MLC-2 phosphorylation in myectomy muscle is $51 \%$ of phosphorylation in donor heart. In the purified myosin samples that were used for in vitro motility measurements, the level of MLC-2 phosphorylation was similarly reduced, by an average of $34 \%$ (Figure 7).

An approximate level of phosphorylation could be calculated from the myofibril gels by comparison with troponin I in donor control, whose phosphorylation level was previously measured as $2.1 \mathrm{~mol} \mathrm{Pi} / \mathrm{mol} ;{ }^{17}$ we estimated that the MLC-2 phosphorylation level was $0.32 \mathrm{~mol} \mathrm{Pi} / \mathrm{mol}$ in donor heart myofibrils.

\subsection{Genotyping of myectomy samples}

The full MYH7 coding sequence for each patient was screened for mutations by amplification and analysis of all exons from paired genomic DNA samples; amplimers with aberrant melting curves were then investigated by bidirectional sequencing. Genomic DNA samples from M3, M4, M7, $M 8$, and M10 revealed no MYH7 mutations, but mutations were detected in $M 1$ and M5. Patient M1 was heterozygous for a $\mathrm{G}>\mathrm{A}$ transition in exon 19, encoding the known hypertrophic cardiomyopathy-causing missense mutation Arg719Gln. Patient M5 was heterozygous for a G>A transition in exon 16, encoding the known hypertrophic cardiomyopathycausing missense mutation Val606Met. 


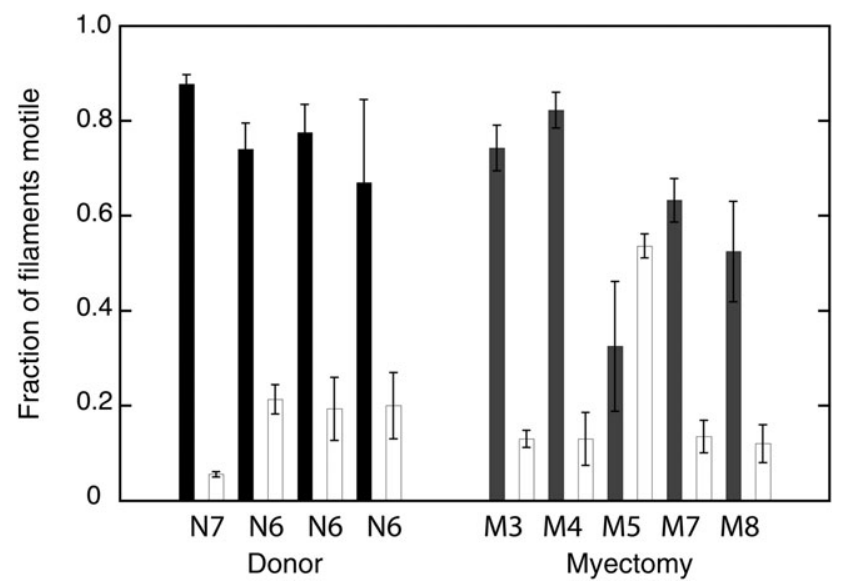

Figure $4 \mathrm{Ca}^{2+}$ regulation of motility of reconstituted thin filaments. Thin filaments were reconstituted with $10 \mathrm{nmol} / \mathrm{L}$ TRITC-phalloidin-actin, $50 \mathrm{nmol} / \mathrm{L}$ human cardiac tropomyosin, and $40 \mathrm{nmol} / \mathrm{L}$ human cardiac troponin. In vitro motility of reconstituted thin filaments was measured at pCa5 (black bars) and pCa9 (grey bars) in dual-chamber cells and the fraction of filaments motile is plotted. $\mathrm{Ca}^{2+}$ regulation of motility was measured with myosin from two donor $(\mathrm{N})$ heart and five myectomy $(\mathrm{M})$ muscle samples. Only M5 showed abnormal regulation.

\section{Discussion}

\subsection{Myocytes from myectomy samples show functional impairment}

Although myectomy patients in the cohort studied were not exhibiting symptoms of end-stage failure, myocytes isolated from these hearts showed functional deficits similar to, and in some conditions greater than, those from patients explanted for end-stage idiopathic or dilated cardiomyopathy. Depression of contraction at physiological $\mathrm{Ca}^{2+}$ concentrations was more pronounced in myectomy-derived myocytes than in failing, and became equivalent to (but not better than) failing as $\mathrm{Ca}^{2+}$ concentration was raised. Similarly, slow relaxation was more evident in myectomyderived myocytes than failing, which in turn were slower than those from non-failing donor heart. Here we described characteristics of a large population of both myectomy and transplant subjects, and it is notable that variances were significantly higher in the myectomy population. This is likely due to different effects of various mutations, which will require detailed analysis when cohorts are sufficient. However, it is clear that impairment of myocyte contraction and relaxation is a general finding in HOCM subjects.

Table 2 M5 compared with N6

\begin{tabular}{llllll}
\hline & $\begin{array}{l}\text { Actin sliding } \\
\text { speed, M5/N6 }\end{array}$ & $\begin{array}{l}\text { Actin- } \\
\text { tropomyosin } \\
\text { sliding speed, } \\
\text { M5/N6 }\end{array}$ & $\begin{array}{l}\text { Actin-tropomyosin- } \\
\text { troponin sliding } \\
\text { speed at pCa5, } \\
\text { M5/N6 }\end{array}$ & $\begin{array}{l}\text { Actin-tropomyosin- } \\
\text { troponin sliding } \\
\text { speed at pCa9, } \\
\text { M5/N6 }\end{array}$ & $\begin{array}{l}\text { Actin-tropomyosin- } \\
\text { troponin fraction } \\
\text { motile at pCa9, } \\
\text { M5/N6 }\end{array}$ \\
\hline Preparation 1 & 1.28 & 1.21 & 1.46 & 1.52 & 2.78 \\
Preparation 2 & 1.44 & 1.18 & 1.43 & 1.32 & 1.01 \\
Preparation 3 & 1.60 & 1.24 & 1.22 & 1.12 & 1.77 \\
\hline
\end{tabular}

Comparison of motility parameters of non-failing heart myosin (N6) and HOCM myosin, M5. M5 has a consistently hypercontractile molecular phenotype.

\section{Myectomy}

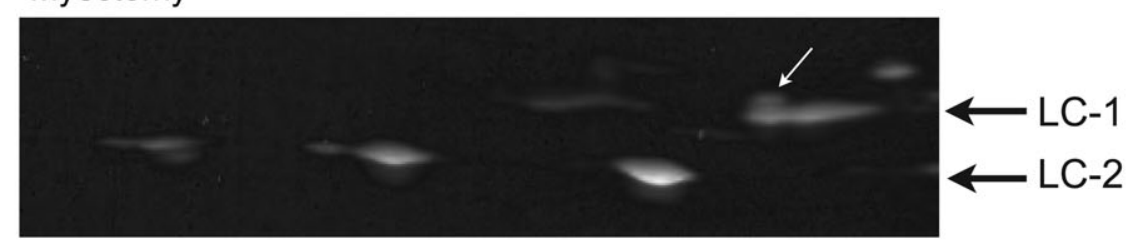

Donor

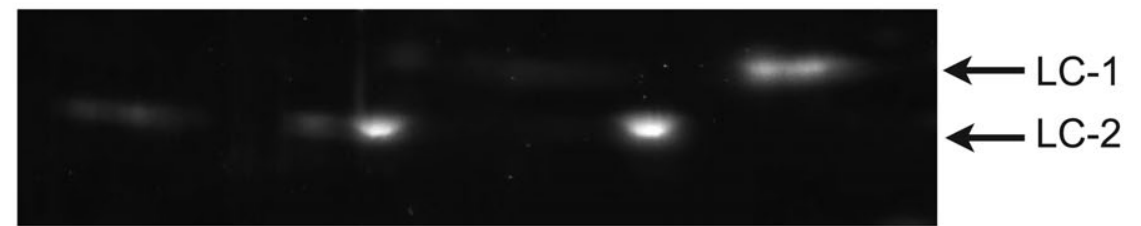

$\mathrm{p} / 4.6$

p/ 5.1

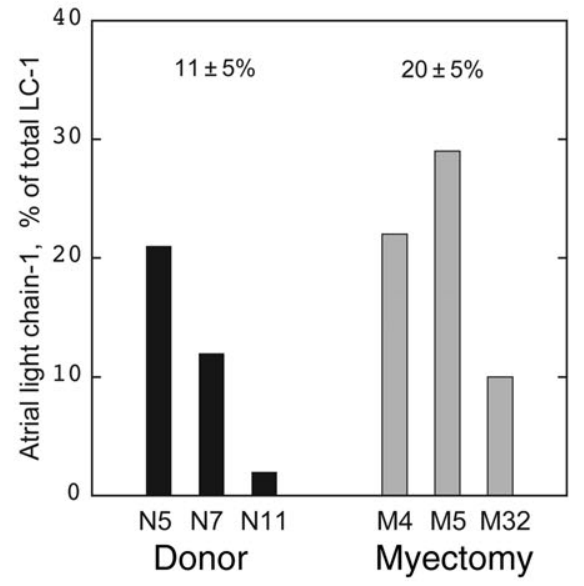

Figure 5 Myosin light chain detection by two-dimensional electrophoresis. Thirty micrograms of myofibrils were separated by $2 \mathrm{D}$ electrophoresis and stained with SYPRO Ruby. The region of the gels showing VLC-1, ALC-1, and MLC-2 are shown. VLC-1 (MYL3-HUMAN) has a pl of 5.03 and Mr of 21800 Da, ALC-1 (MYL4HUMAN) has a pl of 4.98 and $M_{r}$ of $21433 \mathrm{Da}$. ALC-1 was identified in a sample of mouse heart atrium located above and to the left of VLC-1 and was found to be present in all samples tested but more prominent in the myectomy samples (arrow). Densitometry of ALC-1 and VLC-1 spots was performed manually and the ratio of the two isoforms is plotted on the left. Values were quite variable with a trend towards higher ALC-1 content in the myectomy samples. 
(A)

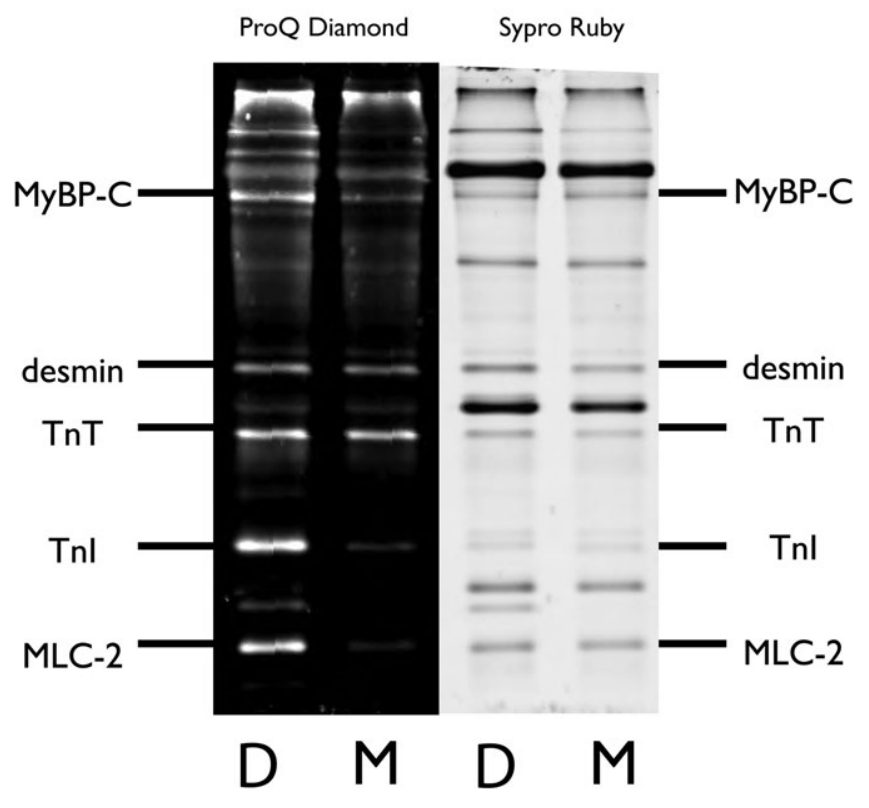

(B)

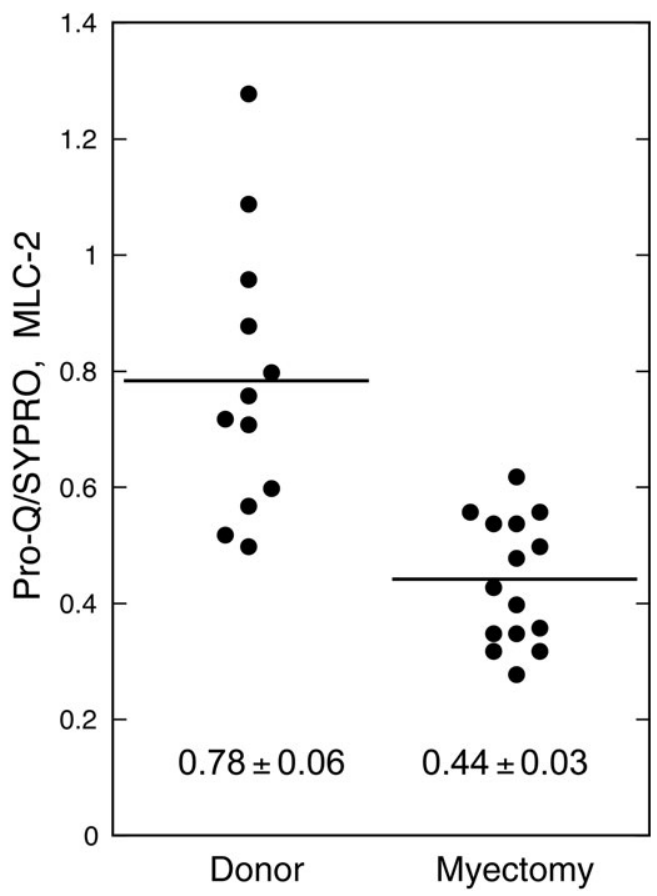

Figure 6 Phosphorylation of human cardiac muscle myofibrils. $(A)$ SDS-PAGE of $10 \mu \mathrm{g}$ myofibrils extracted from donor and myectomy muscle samples, successively stained with Pro-Q Diamond to label phosphoproteins and SYPRO Ruby total protein stain. High levels of phosphorylation are detected in MyBP-C, troponin T, troponin I, and MLC-2. (B) The level of MLC-2 phosphorylation is expressed as the ratio of Pro-Q Diamond band volume:SYPRO Ruby band volume for 12 measurements from 6 donor samples and 15 measurements from 8 myectomy samples. The mean ratios are $0.78 \pm 0.06$ for donor and $0.44 \pm 0.03$ for myectomy samples $(P<0.0001)$.

(A)

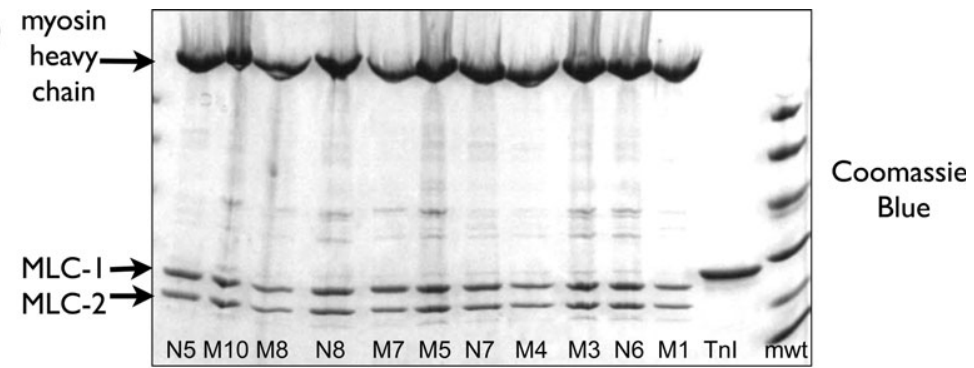

(B)

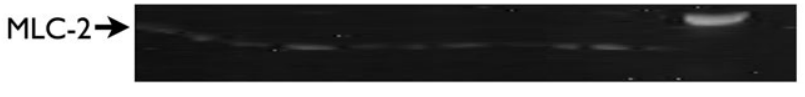

Pro-Q

Diamond

(C)

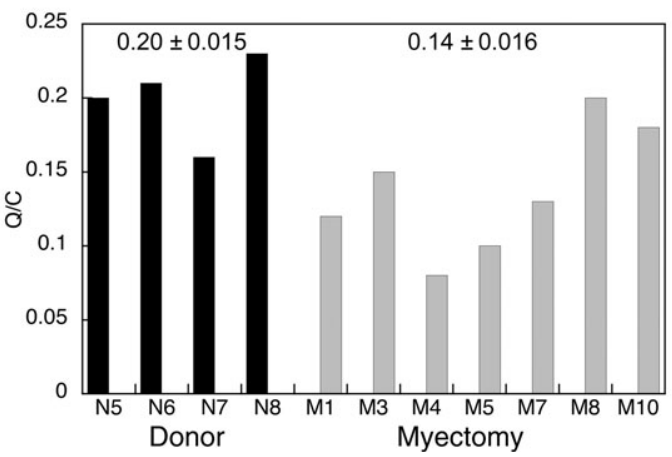

Figure 7 Measurement of myosin light chain-2 phosphorylation in purified myosin. (A) SDS-PAGE of purified myosin, Coomassie Blue staining. (B) Pro-Q Diamond phosphoprotein staining of the same gel showing MLC-2 bands only. (C) Relative MLC-2 phosphorylation levels. Method as described in Figure 6. The mean Pro-Q Diamond band volume/Coomassie Blue band volume ratios $(Q / C)$ are $0.20 \pm 0.015(n=4)$ for donor and $0.14 \pm 0.016(n=7)$ for myectomy samples $(P=0.029)$. 


\subsection{Myosin from myectomy muscle is functionally abnormal}

We then compared the functional and structural properties of myosin extracted from donor heart control, end-stage failing, and hypertrophic human heart muscle obtained from surgical myectomy operations. Myosin could be extracted in high yield and good purity within $3 \mathrm{~h}$ (Figure 2) and was stable for around $2 \mathrm{~h}$ in the in vitro motility assay. The sliding speed of $0.31-0.38 \mu \mathrm{m} / \mathrm{s}$ at $30^{\circ} \mathrm{C}$ was somewhat lower than previous measurements with human heart myosin, ${ }^{8,24}$ however we made measurements in $50 \mathrm{mmol} / \mathrm{L} \mathrm{KCl}$ and used silica-coated glass rather than the more usual nitrocelluose surface. ${ }^{25,26}$ We found a pattern of abnormality in all the myectomy myosin samples; the fraction of filaments moving measured in the in vitro motility assay was consistently 19\% lower than donor heart myosin, whereas the sliding speed, which is considered to be a measure of crossbridge turnover rate, ${ }^{24,26}$ was not significantly different (Figure 3 ). In order to eliminate rigor crossbridges, which would reduce motility, we used an affinity purification step and also blocked damaged myosin in the motility cell with unlabelled actin in the presence of ATP. The persistence of the lower fraction of filaments motile compared with donor muscle myosin when prepared and assayed simultaneously suggests that there is a stable difference in the myectomy myosin.

We examined the level of MLC-2 phosphorylation and found that it was significantly less in the myectomy myosin samples compared with donor heart myosin: $49 \%$ less in myofibrils and 34\% less in purified myosin (Figures 6 and 7). We also measured the relative content of ALC- 1 and VLC-1 in our myosin samples by 2D electrophoresis and observed an increase from $11 \pm 5 \%$ ALC-1 in donor control to $20 \pm 5 \%$ in the myectomy samples (Figure 5).

As these differences were observed in all myectomy samples, but only two (M1, M5) carried an MYH7 mutation, it is evident that they are common consequences of HOCM and not directly related to disease-causing mutations in myosin. It is unlikely that the observed changes in motility are related to the changes seen in myosin light chains since an increased proportion of ALC-1 should increase sliding speed $^{27}$ but no change was observed. The only recorded effect of MLC-2 phosphorylation indicated a decrease in $\mathrm{Ca}^{2+}$ sensitivity ${ }^{28}$ which was not measured here. Thus the defect in myosin is likely to be due to factors that are not related to protein isoform or phosphorylation levels.

Some fresh myectomy muscle samples from the same source were investigated for mechanical performance. In isolated myocytes, the contraction amplitude was reduced and the rate of relaxation was lower than in non-failing heart samples (Figure 1) and in muscle strips there was a negative relationship between isometric force and stimulation frequency. ${ }^{29}$ It is interesting to note that these contractility parameters are similar to those observed with end-stage failing heart or pressure overload ${ }^{21,30}$ rather than the hypercontractile phenotype predicted from molecular studies of hypertrophic cardiomyopathy-causing mutations. ${ }^{6,8}$

\subsection{Myosin abnormalities are similar to failing heart myosin}

Many of the differences in myectomy muscle myosin resemble those observed in failing heart muscle. Comparison of myectomy myosin and failing heart myosin with donor heart by in vitro motility assay shows a similar decrease in the fraction of filaments moving (Figure 3). The lower MLC-2 phosphorylation level (17\% in myectomy muscle compared with $32 \%$ in non-failing) is about the same as that reported for failing heart: $18 \%$, compared with $40 \%$ in donor heart. ${ }^{31}$ The level of MyBP-C phosphorylation is reduced about $50 \%$ in myectomy muscle ${ }^{32}$ and a similarly reduced level of phosphorylation has been observed in failing heart. ${ }^{33}$ We have also observed a low level of MyBP-C and troponin I phosphorylation in both failing heart ${ }^{17,31}$ and myectomy muscle samples. ${ }^{34}$ An increase in ALC-1 content in ventricular myosin from less than $5 \%$ in donor heart to $2-27 \%$ in hypertrophic and failing heart muscle has been reported, ${ }^{27,35}$ comparable with our finding of $11 \%$ in donor and $20 \%$ in myectomy muscle. We did not examine the amount of $\alpha$ and $\beta M H C$ isoforms present, however an investigation by Noguchi et al. ${ }^{36}$ showed that the in vitro motility sliding speed was not different in failing and donor heart myosin despite a variation of the proportion of $\alpha M H C$ from 0 to $13 \%$.

As the combination of increased expression of ALC-1 and decreased phosphorylation of MLC-2, troponin I, and MyBP-C is commonly observed in failing heart muscle, ${ }^{17,33,35}$ it appears that the contractile proteins in myectomy muscle are modified in a similar manner to failing heart. This is compatible with our observations that in both myocytes and in vitro motility assays contractility is similarly dysfunctional in myectomy and failing heart samples (Figures 1 and 3). On the other hand, some functional changes may be different in HOCM and failing heart; for instance, troponin from myectomy muscle shows the same $\mathrm{Ca}^{2+}$ sensitivity as donor heart ${ }^{34}$ rather than the increased $\mathrm{Ca}^{2+}$ sensitivity characteristic of failing heart muscle that is observed both by in vitro motility assay and also in intact skinned muscle. ${ }^{17,31}$ The origin of the reduced fraction motile in myectomy myosin cannot be attributed to changes in isoforms or phosphorylation which would influence the rate of crossbridge turnover. The fraction motile parameter is a measure of the population of active myosins. Inactivation may be due to a specific reason such as a mutation, however in the case of myosin motility we observe it in all samples, so the inactivation is probably a result of protein damage. Damage to myosin may be due to protein oxidation because increased oxidative stress is known to be a feature of hypertrophy. ${ }^{37}$ In support of this idea, it has been shown that motility and ATPase is reduced when skeletal or smooth muscle myosin is oxidized in vitro. ${ }^{38,39}$

Clinically, all the HOCM patients had diastolic dysfunction, but ejection fraction was usually not compromised. This seems at odds with the molecular phenotype of the myectomy samples, i.e. at least as severe as that observed in end-stage failing heart. It is possible that the dysfunction in the interventricular septum, from which our myectomy samples were taken, is not representative of muscle in the rest of the heart. ${ }^{40}$ The defining feature of HOCM is a high pressure difference between the aorta and ventricle due to LVOTO caused by septal hypertrophy, therefore it is possible that local dysfunction may occur as a consequence of pressure overload secondary to the hypertrophy triggered by contractile protein mutations.

\subsection{M5 has a disease-causing MYH7 mutation}

As mutations in MYH7 ( $\beta M H C$ gene) account for up to $25 \%$ of cases of hypertrophic cardiomyopathy, it was likely from the 
outset that at least one of our samples would have a diseasecausing mutation in the $3 M H C$. M5 stood out from the other five myectomy samples assayed as being functionally different (Table 2). In the in vitro motility assay, filament sliding speed was greater than the other myosin samples and relaxation at pCa9 was less complete. Both these properties are characteristic of mutations that cause hypertrophic cardiomyopathy in a variety of contractile proteins that have been studied at the single filament level. ${ }^{5,6} \mathrm{~A}$ higher rate of crossbridge turnover has been recognized as a feature of the few known MHC mutations that have been studied in muscle biopsies. ${ }^{8}$ The prediction that $M 5$ carries a disease-causing hypertrophic cardiomyopathy mutation was confirmed by the subsequent mutation screening, showing that $M 3, M 4, M 7, M 8, M 10$ are all wild-type for the whole of MYH7 but M5 is heterozygous for Val606Met. This mutation is one of the best documented hypertrophic cardiomyopathy-causing alleles. We did not detect a specific functional abnormality in M1, which also has an MYH7 mutation (Arg719Gln), however this sample was only tested for crossbridge turnover rate using pure actin and not for $\mathrm{Ca}^{2+}$ regulation of thin-filament motility which may have shown changes characteristic of HCM mutations. Previous studies by in vitro motility assay indicate $\mathrm{HCM}$ mutations often cause incomplete relaxation and/or increased $\mathrm{Ca}^{2+}$ sensitivity. ${ }^{5-7,27}$ It appears that faster crossbridge turnover rate is one of several diagnostic characteristics of hypertrophic cardiomyopathy mutations.

It should be noted that the decrease in the fraction of filaments motile and changes in myosin light chain expression and phosphorylation are exhibited by all samples including M5 (Figures 3, 5, and 7). This suggests that the hypocontractile state in the interventricular septum of patients with HOCM is not a direct effect of a hypertrophy-inducing mutation. The connection between an altered molecular phenotype such as that observed in M5 and the development of pathological hypertrophy remain unknown. It is anticipated that further functional and structural investigation of myectomy muscle samples, in conjunction with genotyping, will provide data that can start to explain the molecular mechanism of hypertrophic cardiomyopathy.

\section{Supplementary material}

Supplementary material is available at Cardiovascular Research online.

\section{Acknowledgements}

The donor heart samples were provided by Prof. C. Dos Remedios, Sydney, Australia. Technical assistance was provided by O'Neal Copeland, Peter O’Gara, Max Mioulane, Joanne Franklin, Trupti Patel, Allan Zheng and Will Johnson.

\section{Conflict of interest: There are no conflicts of interest.}

\section{Funding}

This work was supported by grants from the British Heart Foundation. The genotyping was supported by the Oxford Partnership Comprehensive Biomedical Research Centre with funding from the Department of Health's NIHR Biomedical Research Centres funding scheme.

\section{References}

1. Redwood CS, Moolman-Smook JC, Watkins H. Properties of mutant contractile proteins that cause hypertrophic cardiomyopathy. Cardiovasc Res 1999;44:20-36.

2. Richard P, Charron P, Carrier L, Ledeuil C, Cheav T, Pichereau C et al. Hypertrophic cardiomyopathy distribution of disease genes, spectrum of mutations, and implications for a molecular diagnosis strategy. Circulation 2003; 107:2227-2232.

3. Van Driest SL, Jaeger MA, Ommen SR, Will ML, Gersh BJ, Tajik AJ et al. Comprehensive analysis of the beta-myosin heavy chain gene in 389 unrelated patients with hypertrophic cardiomyopathy. J Am Coll Cardiol 2004; 44:602-610.

4. Van Driest SL, Vasile VC, Ommen SR, Will ML, Tajik AJ, Gersh BJ et al. Myosin-binding protein C mutations and compound heterozygosity in hypertrophic cardiomyopathy. J Am Coll Cardiol 2004;44:1903-1910.

5. Knollmann BC, Potter JD. Altered regulation of cardiac muscle contraction by troponin $T$ mutations that cause familial hypertrophic cardiomyopathy. Trends Cardiovasc Med 2001;11:206-212.

6. Robinson PJR, Mirza M, Knott A, Abdulrazzak H, Marston S, Watkins H et al. Alterations in thin filament regulation induced by a human cardiac troponin $\mathrm{T}$ mutant that causes dilated cardiomyopathy are distinct from those induced by troponin $\mathrm{T}$ mutants that cause hypertrophic cardiomyopathy. J Biol Chem 2002;277:40710-40716.

7. Redwood C, Lohmann K, Bing W, Esoposito G, Elliott K, Abdulrazzak H et al. Investigation of a truncated troponin $T$ that causes familial hypertrophic cardiomyopathy: $\mathrm{Ca}^{2+}$ regulatory properties of reconstituted thin filaments depend on the ratio of mutant to wild-type peptide. Circ Res 2000;86:1146-1152.

8. Palmiter KA, Tyska MJ, Haeberle JR, Alpert NR, Fananapazir L, Warshaw DM. R403Q and L908V mutant beta-cardiac myosin from patients with familial hypertrophic cardiomyopathy exhibit enhanced mechanical performance at the single molecule level. J Musc Res Cell Motil 2000;21:609-620.

9. James J, Zhang Y, Osonska H, Sanbe A, Klevitsky R, Hewett TE et al. Transgenic modelling of a cardiac troponin I mutation linked to familial hypertrophic cardiomyopathy. Circ Res 2000;87:805-811.

10. Tardiff JC, Factor SM, Tompkins BD, Hewett TE, Palmer BM, Moore RL et al. A truncated troponin T molecule in transgenic mice suggests multiple cellular mechanisms for familial hypertrophic cardiomyopathy. J Clin Invest 1998;101:2800-2811.

11. Ashrafian $\mathrm{H}$, Watkins $\mathrm{H}$. Reviews of translational medicine and genomics in cardiovascular disease: new disease taxonomy and therapeutic implications cardiomyopathies-therapeutics based on molecular phenotype. J Am Coll Cardiol 2007;49:1251-1264.

12. Kohler J, Winkler G, Schulte T, McKenna W, Brenner B, Kraft T. Mutation of the myosin converter domain alters cross-bridge elasticity. Proc Natl Acad Sci USA 2002;99:3557-3562.

13. Kirschner SE, Becker $E$, Antognozzi $M$, Kubis HP, Francino A, Navarro-Lopez F et al. Hypertrophic cardiomyopathy-related betamyosin mutations cause highly variable calcium sensitivity with functional imbalances among individual muscle cells. Am J Physiol Heart Circ Physiol 2005;288:H1242-H1251.

14. Elliott PM, Gimeno JR, Tome MT, Shah J, Ward D, Thaman R et al. Left ventricular outflow tract obstruction and sudden death risk in patients with hypertrophic cardiomyopathy. Eur Heart J 2006;27:1933-1941.

15. Firoozi S, Elliott PM, Sharma S, Murday A, Brecker SJ, Hamid MS et al. Septal myotomy-myectomy and transcoronary septal alcohol ablation in hypertrophic obstructive cardiomyopathy: a comparison of clinical, haemodynamic and exercise outcomes. Eur Heart J 2002;23:1617-1624.

16. Morrow AG, Reitz BA, Epstein SE, Henry WL, Conkle DM, Itscoitz SB et al. Operative treatment in hypertrophic subaortic stenosis: techniques and the results of pre- and postoperative assessments in 83 patients. Circulation 1975;52:88-102.

17. Messer AE, Jacques AM, Marston SB. Troponin phosphorylation and regulatory function in human heart muscle: dephosphorylation of Ser23/24 on troponin I could account for the contractile defect in end-stage heart failure. J Mol Cell Cardiol 2007;42:247-259.

18. Fraser IDC, Marston SB. In vitro motility analysis of actin-tropomyosin regulation by troponin and $\mathrm{Ca}^{2+}$ : the thin filament is switched as a single cooperative unit. J Biol Chem 1995;270:7836-7841.

19. Morano I, Hadicke K, Haase H, Bohm M, Erdmann E, Schaub MC. Changes in essential myosin light chain isoform expression provide a molecular basis for isometric force regulation in the failing human heart. $J \mathrm{Mol}$ Cell Cardiol 1997;29:1177-1187. 
20. Steinberg TH, Agnew BJ, Gee KR, Leung WY, Goodman T, Schulenberg B et al. Global quantitative phosphoprotein analysis using multiplexed proteomics technology. Proteomics 2003;3:1128-1144.

21. Davies CH, Davia K, Bennett JG, Pepper JR, Poole-Wilson PA, Harding SE. Reduced contraction and altered frequency response of isolated ventricular myocytes from patients with heart failure. Circulation 1995;92: 2540-2549.

22. Knott A, Purcell IF, Marston S. In vitro motility analysis of thin filaments from failing and non-failing human hearts induces slower filament sliding and higher $\mathrm{Ca}^{2+}$ sensitivity. J Mol Cell Cardiol 2002;34:469-482.

23. Bing W, Fraser IDC, Marston SB. Troponin I and troponin T interact with troponin $\mathrm{C}$ to produce different $\mathrm{Ca}^{2+}$-dependant effects on actin-tropomyosin filament motility. Biochem J 1997;327:335-340.

24. Malmqvist UP, Aronshtam A, Lowey S. Cardiac myosin isoforms from different species have unique enzymatic and mechanical properties. Biochemistry 2004;43:15058-15065.

25. Kron SJ, Toyoshima YY, Uyeda TQP, Spudich JA. Assays for actin sliding movement over myosin coated surfaces. Methods Enzymol 1991;196: 399-416.

26. Marston S. Random walks with thin filaments: application of in vitro motility assay to the study of actomyosin regulation. J Musc Res Cell Motil 2003;24:149-156.

27. Morano M, Zacharzowski U, Maier M, Lange PE, Alexi-Meskishvili V, Haase $\mathrm{H}$ et al. Regulation of human heart contractility by essential myosin light chain isoforms. J Clin Invest 1996;98:467-473.

28. van der Velden J, Papp Z, Boontje NM, Zaremba R, de Jong JW, Janssen PM et al. The effect of myosin light chain 2 dephosphorylation on $\mathrm{Ca}^{2+}$ sensitivity of force is enhanced in failing human hearts. Cardiovas Res 2003;57:505-514.

29. Gray R, Jacques A, Peters N, McKenna W, Walker J, Mclntyre H et al. Electromechanical properties of isolated myocardium from patients with hypertrophic obstructive cardiomyopathy (HOCM). Circulation 2005;112(17 Supp 15):U149.

30. Mclntyre $\mathrm{H}$, Fry $\mathrm{CH}$. Abnormal action potential conduction in isolated human hypertrophied left ventricular myocardium. J Cardiovasc Electrophysiol 1997;8:887-894.
31. van der Velden J, Papp Z, Zaremba R, Boontje NM, de Jong JW, Owen VJ et al. Increased $\mathrm{Ca}^{2+}$ sensitivity of the contractile apparatus in end-stage human heart failure results from altered phosphorylation of contractile proteins. Cardiovasc Res 2003;57:37-47.

32. Gallon CE, Messer AE, Copeland O, Jacques A, Tsang V, McKenna WJ et al. Post-translational modification of TnT, Tnl, MyBP-C and MLC-2 in HOCM human heart muscle. J Muscle Res Cell Motil 2007, doi:10.1007/ S10974-008-9127-Z abstract\#3:9.

33. El-Armouche A, Pohlmann L, Schlossarek S, Starbatty J, Yeh YH, Nattel S et al. Decreased phosphorylation levels of cardiac myosin-binding protein- $\mathrm{C}$ in human and experimental heart failure. J Mol Cell Cardiol 2007;43:223-229.

34. Jacques A, Messer A, Tsang V, McKenna W, Marston S. Evidence for reduced troponin I phosphorylation and altered troponin function in patients with hypertrophic obstructive cardiomyopathy. J Mol Cell Cardiol 2006;40:939.

35. Palmer BM. Thick filament proteins and performance in human heart failure. Heart Fail Rev 2005;10:187-197.

36. Noguchi T, Camp P Jr, Alix SL, Gorga JA, Begin KJ, Leavitt BJ et al. Myosin from failing and non-failing human ventricles exhibit similar contractile properties. J Mol Cell Cardiol 2003;35:91-97.

37. Seddon M, Looi YH, Shah AM. Oxidative stress and redox signalling in cardiac hypertrophy and heart failure. Heart 2007;93:903-907.

38. Coirault C, Guellich A, Barbry T, Samuel JL, Riou B, Lecarpentier Y. Oxidative stress of myosin contributes to skeletal muscle dysfunction in rats with chronic heart failure. Am J Physiol Heart Circ Physiol 2006; 292:H1009-H1017.

39. Penheiter AR, Bogoger M, Ellison PA, Oswald B, Perkins WJ, Jones KA et al. $\mathrm{H}_{2} \mathrm{O}_{2}$-induced kinetic and chemical modifications of smooth muscle myosin: correlation to effects of $\mathrm{H}_{2} \mathrm{O}_{2}$ on airway smooth muscle. J Biol Chem 2007;282:4336-4344.

40. Yamazaki T, Suzuki J, Shimamoto R, Tsuji T, Ohmoto Y, Toyo-Oka T et al. Focalized contractile impairment at hypertrophied myocardium proven in consideration of wall stress in patients with hypertrophic cardiomyopathy. Int Heart J 2006;47:247-258. 